\title{
Statistical analysis of automatically detected ion density variations recorded by DEMETER and their relation to seismic activity
}

\author{
Michel Parrot
}

Laboratoire de Physique et Chimie de l'Environnement et de l'Espace, Université d'Orléans, CNRS, Orléans, France

\author{
Article history \\ Received july 4, 2011; accepted September 26, 2011. \\ Subject classification: \\ Ionosphere, Satellite, Earthquake interactions and probability.
}

\section{ABSTRACT}

Many examples of ionospheric perturbations observed during large seismic events were recorded by the low-altitude satellite DEMETER. However, there are also ionospheric variations without seismic activity. The present study is devoted to a statistical analysis of the night-time ion density variations. Software was implemented to detect variations in the data before earthquakes world-wide. Earthquakes with magnitudes $>4.8$ were selected and classified according to their magnitudes, depths and locations (land, close to the coast, or below the sea). For each earthquake, an automatic search for ion density variations was conducted from 15 days before the earthquake, when the track of the satellite orbit was at less than $1,500 \mathrm{~km}$ from the earthquake epicenter. The result of this first step provided the variations relative to the background in the vicinity of the epicenter for each 15 days before each earthquake. In the second step, comparisons were carried out between the largest variations over the 15 days and the earthquake magnitudes. The statistical analysis is based on calculation of the median values as a function of the various seismic parameters (magnitude, depth, location). A comparison was also carried out with two other databases, where on the one hand, the locations of the epicenters were randomly modified, and on the other hand, the longitudes of the epicenters were shifted. The results show that the intensities of the ionospheric perturbations are larger prior to the earthquakes than prior to random events, and that the perturbations increase with the earthquake magnitudes.

\section{Introduction}

A substantial number of effects in the Earth's atmosphere and the ionosphere that are possibly associated with earthquakes have been revealed over the past 20 years. Ionospheric phenomena and their correlation with seismic events have been examined in numerous experimental studies. The seismo-electromagnetic effects include: electromagnetic emissions in a large frequency range, perturbations of ionospheric layers, anomalies in the records of very low frequency (VLF) transmitter signals, night airglow observations, and heating. The hypotheses of the generation mechanisms of precursors to earthquakes are mainly related to: wave production by rock compression, diffusion of water in the epicentral area, and redistribution of electric charges at the surface of the Earth and then in the Earth's atmospheric system.

These hypotheses and modeling have already been published, and they can be found for example in monographs published by Hayakawa and Fujinawa [1994], Hayakawa [1999] and Hayakawa and Molchanov [2002], in books by Gokhberg et al. [1995] and Pulinets and Boyarchuk [2004], in special issues of journals [Parrot and Johnston 1989, 1993, Hayakawa 2002, Hayakawa et al. 2004], and in reviews by Molchanov [1993], Hayakawa [1997], Freund et al. [2006], Tronin [2006], Ouzounov et al. [2007], Pulinets [2009] and Harrison et al. [2010], and in references therein.

The DEMETER (Detection of Electro-Magnetic Emissions Transmitted from Earthquake Regions) satellite was the first satellite with a complete payload that was specifically dedicated to this scientific objective [Parrot 2006]. With its data, many ionospheric perturbations have been observed in relation to earthquakes, and examples can be found in Parrot et al. [2006], Ouyang et al. [2008], Zhu et al. [2008], Zeng et al. [2009], Zhang et al. [2009a,b,c, 2010a,b,c), Akhoondzadeh et al. [2010], Bankov et al. [2010], He et al. [2010], Yufei et al. [2010], Zlotnicki et al. [2010] and Píša et al. [2011].

However, it needs to be kept in mind that all of the measured parameters also show variations in the absence of seismic activity, as the mid-latitude and equatorial ionosphere is affected by a number of other sources of perturbations, and primarily by solar activity. Therefore, only a statistical study covering many events will be able to show the general behavior of these ionospheric perturbations, and will help us to define a signature of ionospheric perturbations prior to earthquakes. This is possible with the DEMETER data, because the lifetime of the mission is more than 6 years.

The DEMETER payload is briefly described in Section 2. In Section 3 the events that occurred before the main 
shocks of earthquakes are shown. The statistical analysis and the results are presented in Section 4. Discussion and conclusions are provided in Section 5.

\section{The DEMETER satellite}

DEMETER is a low-altitude satellite $(710 \mathrm{~km})$ that was launched in June 2004 into a polar and circular orbit. It can measure the electromagnetic waves and plasma parameters all around the globe, except in the auroral zones [Parrot 2006]. The altitude of the satellite was decreased to $660 \mathrm{~km}$ in December 2005. The scientific mission of DEMETER came to an end in December 2010. Due to technical reasons, the data were only recorded at invariant latitudes of less than $65^{\circ}$. The orbit of DEMETER is nearly sun-synchronous and the up-going half-orbits correspond to night-time (22.30 LT), whereas the down-going half-orbits correspond to day-time $(10.30 \mathrm{LT})$. As nearly sun-synchronous, this means that everyday the satellite did not return to exactly above the same point, but to above the same area (it could be at more than $1,000 \mathrm{~km}$ from the point it flew over in the previous days). The payload of DEMETER included an instrument known as a thermal plasma analyzer (IAP; Instrument Analyseur de Plasma). The aim of the IAP was to measure the main parameters of the thermal ion population; i.e. the densities of the major ionospheric ions, $\mathrm{H}+, \mathrm{He}+$ and $\mathrm{O}+$, their temperature, and the ion flow velocity from the Earth's frame of reference. The IAP provided ion densities with a 4$s$ time resolution. Details of the IAP experiment can be found in Berthelier et al. [2006].

\section{Examples of ionospheric perturbations}

Figures 1 and 2 show a remarkable event that was recorded by DEMETER before the M 8 Samoa earthquake that occurred on September 29, 2009, at 17.48.11 UT (location $\left.15.51^{\circ} \mathrm{S}, 187.97^{\circ} \mathrm{E}\right)$. Figure 1 corresponds to data recorded on September 22, 2009 (7 days before the earthquake) whereas data in Figure 2 have been recorded on September 28, 2009 (1 day before the earthquake). Both of these Figures have the same presentation. The top panels in Figures 1 and 2 show the $\mathrm{O}+$ ion density, and the bottom panels show the earthquake occurrences along the satellite orbit. These bottom panels also show the satellite closest approach to past and future earthquake epicenters that are within $2,000 \mathrm{~km}$ of the DEMETER orbit. The Y-axis represents the distances D between the epicenters and the satellite, from $750 \mathrm{~km}$ up to $2,000 \mathrm{~km}$. The symbols are filled green squares for postseismic events and filled red triangles for pre-seismic events. The color scale on the right of these bottom panels represents the time interval between the earthquakes and the DEMETER orbit, with color gradation from $>30$ days down to a $0-6 \mathrm{~h}$ interval. The symbol sizes correspond to earthquakes of magnitudes 5-6, 6-7, and $>7$. The red triangles indicate the closest approach to the Samoa earthquake and the many aftershocks, with their elongated positions indicating that the DEMETER orbit was almost parallel to the rupture fault. The density presents a clear fluctuation when the satellite arrives above the future epicenter. Other ionospheric perturbations for this earthquake were published by Akhoondzadeh et al. [2010]. By examining the three

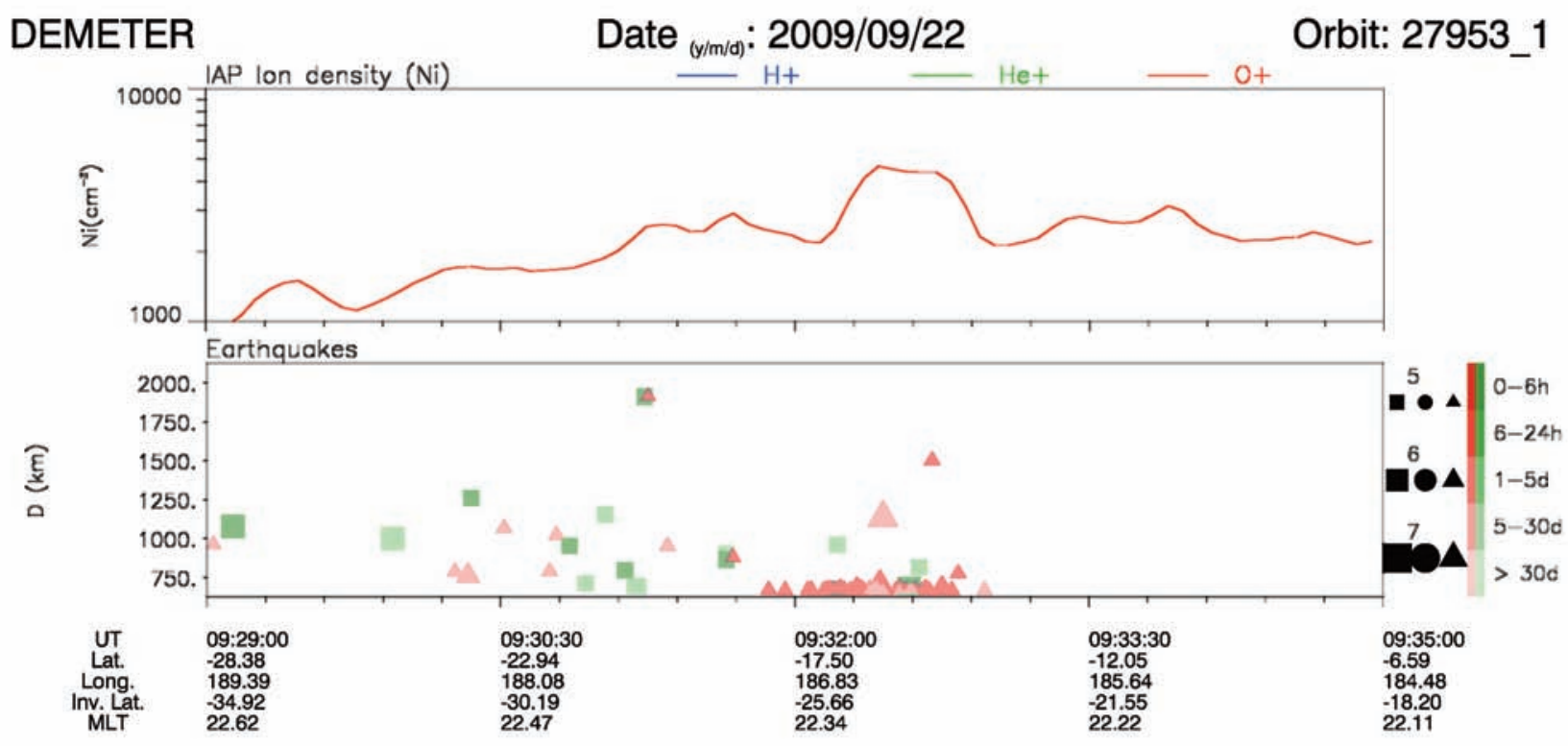

Figure 1. Data recorded on September 22, 2010, between 09.29.00 UT and 09.35.00 UT, 7 days before a powerful earthquake in the Samoa Islands. Top panel, ion density, where due to the scale, only the density of $\mathrm{O}^{+}$ions is seen, as the majority. Bottom panel, distance and magnitudes of forthcoming earthquakes, as a function of time. Red triangles, future main shocks and aftershocks; green symbols, past earthquakes (see text for details). Below the panels, details of the observations (during night-time along the rupture zone of the earthquakes). 
DEMETER

Date $_{(y / m /())}: 2009 / 09 / 28$

Orbit: 28041_1

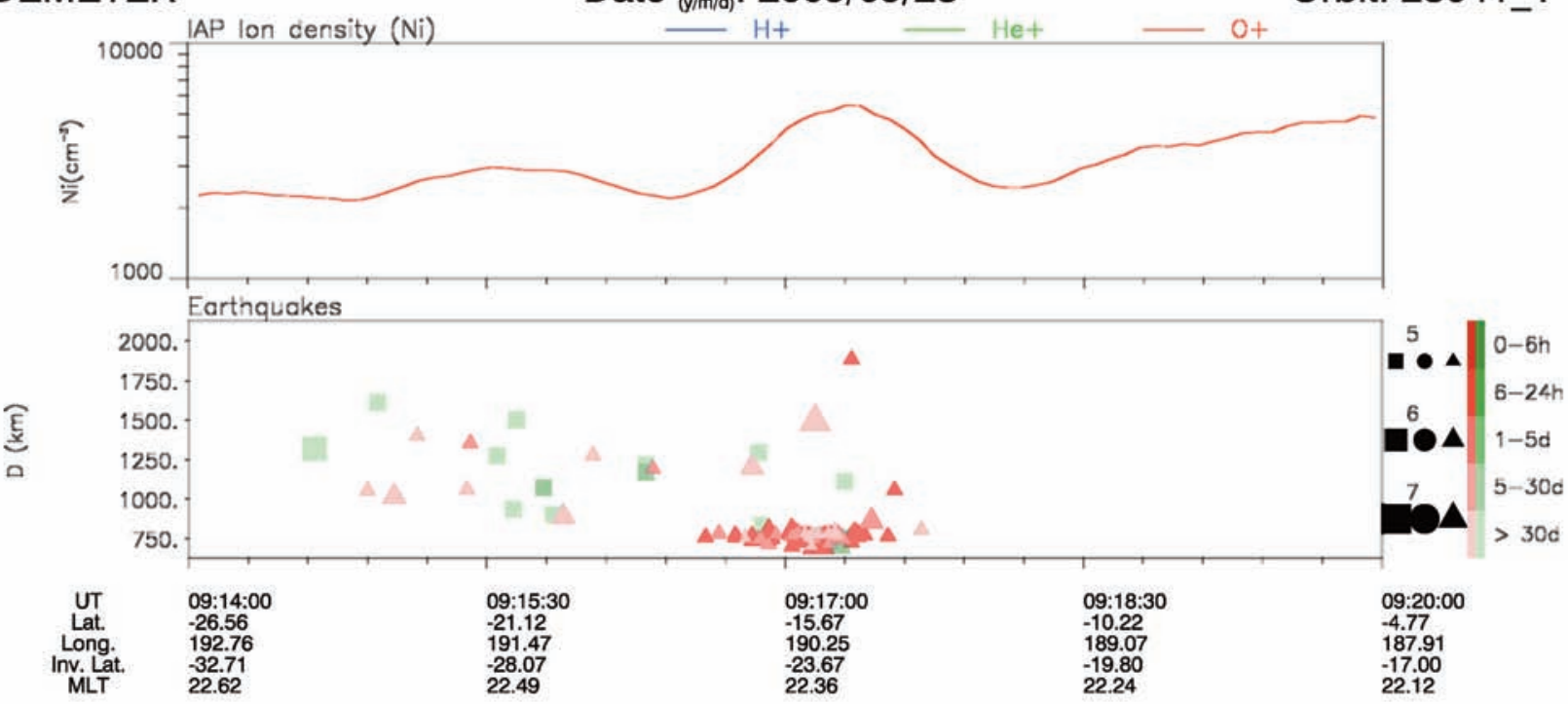

Figure 2. Data recorded on September 28, 2010, between 09.14.00 UT and 09.20.00 UT, 1 day before a powerful earthquake in the Samoa Islands. See Figure 1 for details.

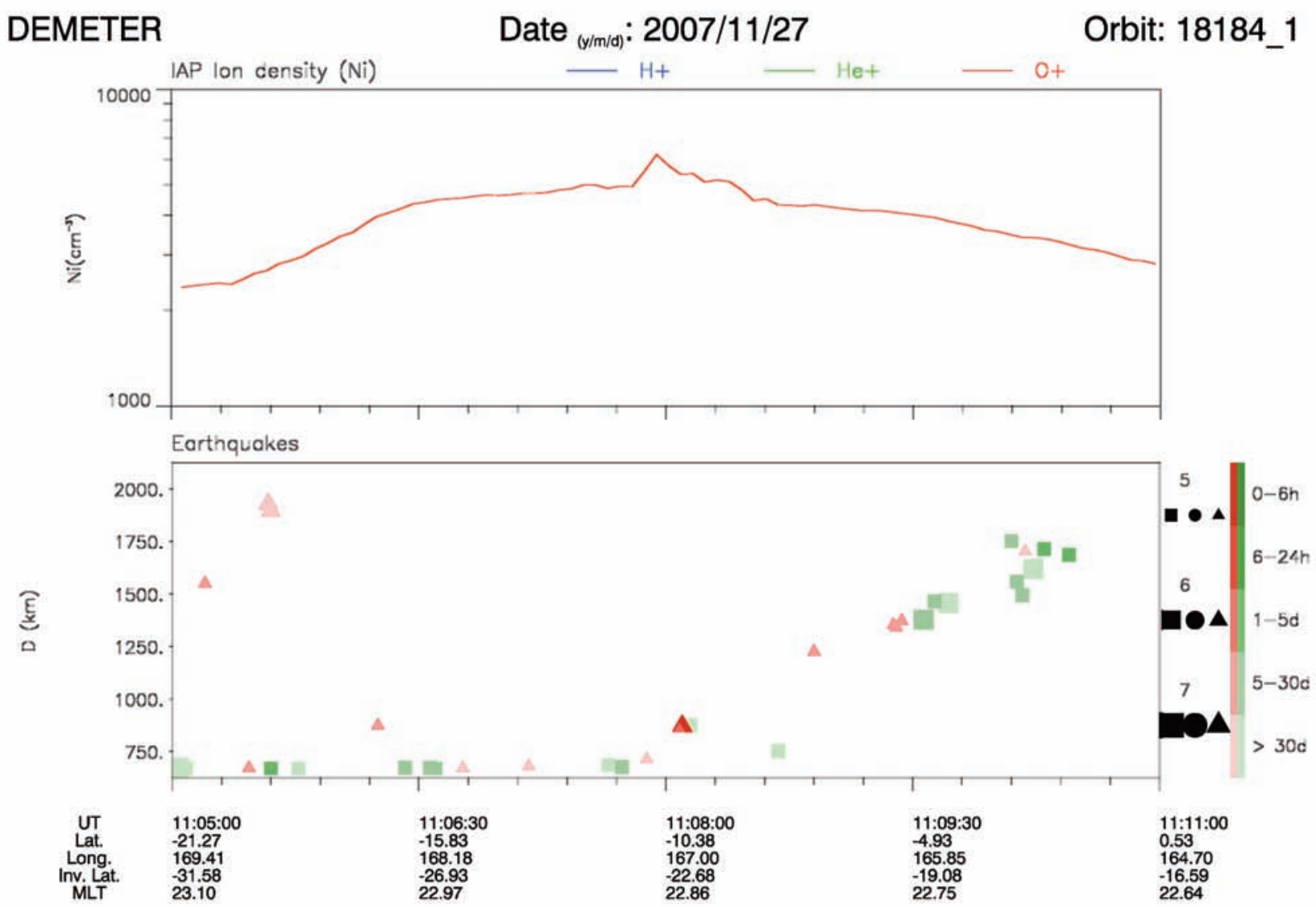

Figure 3. Data recorded on November 27, 2007, between 11:05:00 UT and 11:11:00 UT, a few tens of minutes before a M 6.6 earthquake, which occurred at 11:50:02 UT (latitude, $-11.02^{\circ} \mathrm{S}$; longitude, $162.17^{\circ} \mathrm{E}$; depth, $41.6 \mathrm{~km}$ ). See Figure 1 for details.

preceding months, they showed that these perturbations were very uncommon in this area at that time.

Many other ionospheric perturbations were recorded by DEMETER, and even for earthquakes of smaller magnitudes. These were generally observed a few hours before the moderate earthquakes. An example is given in Figure 3. All of these observations were performed during the night-time. 


\section{The statistical analysis}

It must be said that the variations in the ionospheric parameters are not only due to earthquakes. There are numerous possibilities of ionospheric perturbations that can come from other sources (solar activity, acoustic gravity waves, traveling ionospheric disturbances, plasma dynamics, and large meteorological phenomena). In the examples that have been given in the past, great care was taken to show that these ionospheric variations that are associated with seismic activity are uncommon at these locations and at the times when they were observed.

On the other hand, with satellite data, we do not find ionospheric perturbations for all earthquakes. This might be due to the crust composition and soil configuration. However, we also do not expect to have continuous ionospheric perturbations, and with a single satellite we are 'above' a given future epicenter for only 3 min per day (nighttime half-orbit). Here, the term 'above' refers to a distance of less than $1,500 \mathrm{~km}$.

For these two above-mentioned reasons, we preferred to search for possible influences of seismic activity on the ionosphere using a statistical analysis. Automatic software to detect density fluctuations was developed. The inputs are the earthquake list and the DEMETER data. Earthquakes with magnitudes $>4.8$ were selected, and for each of these, we associated a parameter related to the position of the epicenter: below the sea or inland, and close to the coast. During the period considered (August 2004 to October 2009), there were 17,366 such earthquakes. The software searched for the data of the orbits that were close to the epicenters (less than 1,500 km) between 0 and 15 days before each of the earthquakes. It then retains one night-time half-orbit per day, whereby if there were two orbits, it retains the closest one. It is possible that for a given earthquake there was no half-orbit for that given day because the data were not recorded or because the half-orbit was too far away. To detect variations, the software considers the DEMETER ion density data over the $3 \mathrm{~min}$ around the closest approach to the future epicenter of an earthquake. The data are smoothed and variations (crests or troughs) are searched using change in the derivative sign.

At the end, the software produces a final database with the results. For each earthquake, the first line of the database gives the information about its date, time, latitude, longitude, magnitude, depth and position. The following 15 lines give the information on the data recorded along the half-orbits. The second line relates to the $24 \mathrm{~h}$ before the earthquake, then the third line to the $-48 \mathrm{~h}$ to $-24 \mathrm{~h}$ period, and so on. The information provided includes the half-orbit number, the date and time where the half-orbit was closest to the epicenter, the date, time and position when the automatic software detected any variation in the ion densities, and parameter $\mathrm{A}$, which gives the percentage of these variations relative to the background. The software could also detect no variations.

To evaluate the results of the automatic detection software working with the earthquake list, we considered two other lists with random data. First, we took the list of the earthquakes and randomly changed their latitudes and longitudes (keeping the same times). The resulting database after the software application is called RAND1. Secondly, we took the same list of earthquakes and only shifted their longitudes $25^{\circ}$ to the west (keeping the same latitudes and times). After the software application, this third database is called RAND2. This shift of the longitude is because, on the one hand, most of the earthquakes were concentrated around the equator, and on the other hand, it is known that during the night-time, natural occurrences of ionospheric perturbations are also more concentrated around the equator. Then with RAND2 we have a database that fits more with the reality concerning the positions of the earthquakes and the possible ionospheric perturbations due to usual geophysical activities.

To reduce the effects of solar activity, we eliminated the data when the $\mathrm{kp}$ index was $>3+$. We also do not take into account the aftershock data when the time of the aftershock is too close to the time of the main shock, in order not to mix pre-seismic and post-seismic effects. It is known that at the exact time of an earthquake, you can have propagation of an acoustic gravity wave that can perturb the ionosphere [see for example, Garcia et al. 2005]. Then, if $\mathrm{N}$ is the number of days between the main shock and the aftershock, and if $\mathrm{N}$ $<15$, then we have only considered the aftershock data for $\mathrm{N}-1$ days before this aftershock.

This automatic software to detect variations is certainly not perfect, because the shapes of any ionospheric perturbations might be very different. We have examples with very sharp peaks or very smooth peaks in the ion density. However, we ran the software in the same way on the three lists to search for ionospheric perturbations and to produce three databases (earthquakes, RAND1 and RAND2).

The largest values of A were selected in each data bases (earthquake and random) from the 15 days before each earthquake (each event for the random databases). A distinction was made regarding the positions of the earthquakes (all epicenters, with epicenters below the sea, with epicenters inland or close to the coast). To check whether the ionospheric perturbations depend on the earthquake magnitudes, the results are displayed as functions of several magnitude intervals ([4.8, 5.0], ]5.0, 5.5], ]5.5, 6.0], and ]6.0, $9.0]$ ). This selection of intervals was designed to have enough events in each case for the statistical analysis. Even if it has no meaning, this was also done for the random databases, to have several draws in these databases. The characteristics of the statistical distributions of these largest values of A were evaluated using the kurtosis and the skewness parameters. It 
appears that the kurtosis is always much less than 3 and the skewness is not close to 0 (see Tables 1 and 2). This means that the distributions of these data do not follow a normal law and that it is better to use a median value than a mean value of parameter A. Table 1 gives the results obtained with the RAND1 and RAND2 databases. As expected, larger perturbations (median values) are observed with the RAND2 database, and in the following, all of the comparisons are carried out with this RAND2 database. To obtain a reference median value, 20 draws were made in the RAND2 database (varying the false magnitudes and depths). All of these median values were averaged and a standard deviation was calculated. Table 1 gives the events that occurred everywhere, although

\begin{tabular}{ccccc}
\hline Statistic & \multicolumn{4}{c}{ Magnitude range } \\
\cline { 2 - 5 } & ] $4.8,5.0]$ & ] $5.0,5.5]$ & ] $5.5,6.0]$ & ] $6.0,9.0]$ \\
\hline RAND1 & & & & \\
Number of events & 7576 & 4347 & 1259 & 570 \\
Median & 7.49 & 7.52 & 7.89 & 7.12 \\
Kurtosis & 1.548 & 1.565 & 1.669 & 2.456 \\
Skewness & 1.145 & 1.160 & 1.124 & 1.373 \\
\hline RAND2 & & & & \\
Number of events & 6218 & 3460 & 987 & 415 \\
Median & 7.68 & 7.77 & 8.03 & 7.19 \\
Kurtosis & 0.719 & 0.843 & 0.805 & 0.346 \\
Skewness & 0.931 & 0.966 & 0.897 & 0.878 \\
\hline
\end{tabular}

Table 1. Statistics relating to the maximum intensities A of perturbations (see text for explanations) according to the RAND1 and RAND2 random databases with events occurring everywhere.

\begin{tabular}{ccccc}
\hline Statistic & \multicolumn{4}{c}{ Magnitude } \\
\cline { 2 - 5 } & ] $4.8,5.0]$ & ] $5.0,5.5]$ & ] $5.5,6.0]$ & ] $6.0,9.0]$ \\
\hline All earthquakes & & & & \\
Number of earthquakes & 6332 & 3506 & 1032 & 420 \\
Median & 8.16 & 8.23 & 8.47 & 9.27 \\
Kurtosis & 0.437 & 0.598 & 0.003 & -0.032 \\
Skewness & 0.812 & 0.809 & 0.686 & 0.696 \\
\hline Sea earthquakes & & & & \\
Number of earthquakes & 1734 & 1084 & 328 & 98 \\
Median & 8.66 & 8.69 & 8.33 & 10.48 \\
Kurtosis & 0.628 & 0.457 & 0.021 & -0.582 \\
Skewness & 0.830 & 0.777 & 0.650 & 0.474 \\
\hline Inland earthquakes & & & & \\
Number of earthquakes & 4598 & 2422 & 704 & 322 \\
Median & 7.94 & 7.93 & 8.53 & 8.96 \\
Kurtosis & 0.373 & 0.656 & -0.086 & 0.201 \\
Skewness & 0.812 & 0.809 & 0.687 & 0.774 \\
\hline
\end{tabular}

Table 2. Statistics relating to the maximum intensities A of perturbations for the earthquake database (see text for explanations). The results are given as functions of the earthquake epicentre positions and magnitudes.

\begin{tabular}{ccc}
\hline Statistic & \multicolumn{2}{c}{ Depth } \\
\cline { 2 - 3 } & $\leq 40 \mathrm{~km}$ & $>40 \mathrm{~km}$ \\
\hline All earthquakes & 313 & 107 \\
Number of earthquakes & 9.35 & 8.64 \\
Median & & \\
Sea earthquakes & 75 & 23 \\
Number of earthquakes & 10.84 & 8.64 \\
Median & & \\
Inland earthquakes & 238 & 84 \\
Number of earthquakes & 8.96 & 8.84 \\
Median &
\end{tabular}

Table 3. Statistics relating to the maximum intensities $A$ of the perturbations for powerful earthquakes (] $6.0,9.0]$ ) as a function of their locations and depths.

similar calculations were carried out for events below the sea and for inland events. For the RAND2 database, the final averaged median values are $7.82 \pm 0.61$ (all events), $8.21 \pm 1.23$ (events below the sea), and $7.46 \pm 0.34$ (inland events). These values can be compared with the median values calculated from the real earthquake database, which are given in Table 2. This Table 2 gives for each magnitude interval and for each epicenter position, the median values of each distribution. It can be seen that the maximum perturbations increase with the magnitude, as was expected, and that they are more intense for earthquakes that occurred below the sea. These results are significant if they are larger than the average median value for random events plus the variance ( 8.43 for all events, 9.44 for sea events, 7.80 for inland events). This is true for powerful earthquakes (Table 2, last column) and all inland earthquakes.

The influence of the depth was checked for powerful earthquakes (] $6.0,9.0])$, and these results are shown in Table 3. Table 3 can be compared with the last column of Table 2 (identical values in the tables are just by chance). As expected, the perturbations are not so important for deep earthquakes $(>40 \mathrm{~km})$.

\section{Discussion and conclusions}

A few examples of ionospheric perturbations prior to seismic activity have been presented in this study. These perturbations occur in close vicinity of the earthquake epicenters, and a few hours to a few days before the shocks. However, many other phenomena can perturb the ionosphere, and as people might doubt the relationships between the ionosphere and the Earth's crust despite the various mechanisms briefly mentioned in the Introduction, a statistical analysis was performed while considering a huge number of events.

These statistics show that ionospheric perturbations are more important close to the epicenters of future inland 
earthquakes than prior to events at random positions. It also indicates that the intensities of these perturbations is more important when the magnitudes of the earthquakes are greater.

One surprising result is that there are more intense perturbations for earthquakes with an epicenter below the sea. However, the comparison with the random database indicates that this variation is inside the normal fluctuation range (mean \pm standard deviation). This can be linked to a possible mechanism of generation of these natural ionospheric perturbations. For instance, it is known that the electrical conductivity is larger above the sea.

Finally, deep earthquakes $(>40 \mathrm{~km})$ do not produce ionospheric perturbations. The presented statistical analysis agrees with previous studies that have reported local increases in particle densities in time and positions close to forthcoming earthquakes [see for example, Liu et al. 2009, Kon et al. 2011].

Acknowledgements. This study was supported by the Centre National d'Etudes Spatiales. It is based on observations with the plasma analyzer on DEMETER. The author thanks J.J. Berthelier, the PI of this instrument, for the use of the data, and Pauline Le Maire for help in data handling. The study leading to these results also received funding from the European Community Seventh Framework Programme (FP7/20072013), under grant agreement $\mathrm{N}^{\circ} 262005$.

\section{References}

Akhoondzadeh, M., M. Parrot and M.R. Saradjian (2010). Electron and ion density variations before strong earthquakes $(/ \mathrm{M} />6.0)$ using DEMETER and GPS data, Nat. Haz. Earth Sys., 10, 7-18.

Bankov, L.G., M. Parrot, R.A. Heelis, J.-J. Berthelier, P.G. Marinov and A.K. Vassileva (2010). DEMETER and DMSP satellite observations of the disturbed $\mathrm{H}^{+} / \mathrm{O}^{+}$ratio caused by Earth's seismic activity in the Sumatra area during December 2004, Adv. Space Res., 46, 419-430.

Berthelier, J.J., M. Godefroy, F. Leblanc, E. Seran, D. Peschard, P. Gilbert and J. Artru (2006). IAP, the thermal plasma analyzer on DEMETER, Planet. Space Sci., 54, 487-501.

Freund, F.T., A. Takeuchi and B.W.S. Lau (2006). Electric currents streaming out of stressed igneous rocks - A step towards understanding pre-earthquake low frequency EM emissions, Phys. Chem. Earth, Parts A/B/C, 31, 389-396.

Garcia, R., F. Crespon, V. Ducic and P. Lognonné (2005). Three-dimensional ionospheric tomography of postseismic perturbations produced by the Denali earthquake from GPS data, Geophys. J. Int., 163, 1049-1064; doi: 10.1111/j.1365-246X.2005.02775.

Gokhberg, M.B., V.A. Morgounov and O.A. Pokhotelov (1995). Earthquake Prediction: Seismo-Electromagnetic Phenomena, Gordon and Breach Science Publishers.
Harrison, R.G., K.L. Aplin and M.J. Rycroft (2010). Atmospheric electricity coupling between earthquake regions and the ionosphere, J. Atmos. Sol. Terr. Phys., 72, 376-381.

Hayakawa, M. and Y. Fujinawa (1994). Electromagnetic Phenomena Related to Earthquake Prediction, edited by M. Hayakawa and Y. Fujinawa, Terra Sci. Pub. Co., Tokyo.

Hayakawa, M. (1997). Electromagnetic Precursors of Earthquakes: Review of Recent Activities. Review of Radio Science, 1993-1996, Oxford University Press, Oxford, 807-818

Hayakawa, M. (Ed.) (1999). Atmospheric and Ionospheric Electromagnetic Phenomena associated with Earthquakes, Terra Sci. Pub. Co., Tokyo.

Hayakawa, M. (Ed.) (2002). Seismo-electromagnetics, Special Issue, J. Atmos. Electr., 22, 111-300.

Hayakawa, M. and O.A. Molchanov (Eds.) (2002). SeismoElectromagnetics: Lithosphere-Atmosphere-Ionosphere Coupling, Terra Sci. Pub. Co., Tokyo.

Hayakawa, M., O.A. Molchanov, P. Biagi and F. Vallianatos, (Eds.) (2004). Seismo-electromagnetics and related phenomena, Phys. Chem. Earth, 29, 287-662.

He, Y., D. Yang, J. Qian M. and Parrot (2011). Response of the ionospheric electron density to different types of seismic events, Nat. Hazards Earth Sys., 11, 2173-2180; doi: 10.5194/nhess-11-2173-2011.

Yufei, H., D. Yang, R. Zhu, J. Qian and M. Parrot (2010). Variations of electron density and temperature in ionosphere based on the DEMETER ISL data, Earthqu. Sci., 23, 349-355; doi: 10.1007/s11589-010-0732-8.

Kon, S., M. Nishihashi and K. Hattori (2011). Ionospheric anomalies possibly associated with $\mathrm{M} \geq 6.0$ earthquakes in the Japan area during 1998-2010: Case studies and statistical study, J. Asian Earth Sci., 41, 410-420; doi: 10.1016/j.jseaes.2010.10.005.

Liu, J.Y., Y.I. Chen, C.H. Chen, C.Y. Liu, C.Y. Chen, M. Nishihashi, J.Z. Li, Y.Q. Xia, K.I. Oyama, K. Hattori and C.H. Lin, (2009). Seismo-ionospheric GPS total electron content anomalies observed before the 12 May 2008 Mw 7.9 Wenchuan earthquake, J. Geophys. Res., 114, A04320; doi: 10.1029/2008JA013698.

Molchanov, O.A. (1993). Wave and plasma phenomena inside the ionosphere and magnetosphere associated with earthquakes, In: Review of Radio Science 1990-1992, edited by W. Ross Stone, Oxford University Press, Oxford, 591-600.

Ouyang, X.-Y, X.-M. Zhang, X.-H. Shen, J. Liu, J.-D. Qian, J. Cai and S.-F. Zhao (2008). Ionospheric Ne disturbances before 2007 Puer, Yunnan, China, earthquake, Acta Seismol. Sinica, 21, 425-437; doi: 10.1007/s11589-0080425-8.

Ouzounov, D., D. Liu, K. Chunli, G. Cervone, M. Kafatos 
and P. Taylor (2007). Outgoing long-wave radiation variability from IR satellite data prior to major earthquakes, Tectonophysics, 431, 211-220.

Parrot, M. and M. Johnston (1989). Seismoelectromagnetic Effects, Phys. Earth Planet. Int., 57, 1-177.

Parrot, M. and M. Johnston (1993). Seismoelectromagnetic Effects, Phys. Earth Planet. Int., 77, 1-141.

Parrot, M. (Ed.) (2006). First results of the DEMETER micro-satellite, Planet. Space Sci., 54, 411-557.

Parrot, M., J.J. Berthelier, J.P. Lebreton, J.A. Sauvaud, O. Santolík and J. Blecki (2006). Examples of unusual ionospheric observations made by the DEMETER satellite over seismic regions, Phys. Chem. Earth, 31, 486-495; doi: 10.1016/j.pce.2006.02.011.

Píša, D., M. Parrot, and O. Santolík (2011), Ionospheric density variations recorded before the $2010 \mathrm{Mw} 8.8$ earthquake in Chile, J. Geophys. Res., 116, A08309; doi: 10.1029/2011JA016611.

Pulinets, S.A. and K.A. Boyarchuk (2004). Ionospheric Precursors of Earthquakes, Springer, Hedelberg, New York.

Pulinets, S.A. (2009). Physical mechanism of the vertical electric field generation over active tectonic faults, Adv. Space Res., 44, 767-773, 2009; doi: 10.1016/j.asr.2009.04.038.

Tronin, A.A. (2006) Remote sensing and earthquakes: A review, Phys. Chem. Earth, 31, 138-142.

Zeng, Z.-C., B. Zhang, G.-Y. Fang, D.-F. Wang and H.-J. Yin (2009). The analysis of ionospheric variations before Wenchuan earthquake with DEMETER data, Chinese J. Geophys., 52, 11-19.

Zhang, X., J. Qian, X. Ouyang, X. Shen, J. Cai and S. Zhao (2009a). Ionospheric electromagnetic perturbations observed on DEMETER satellite before Chile M 7.9 earthquake, Earthq. Sci., 22, 251-255.

Zhang, X., J. Qian, X. Ouyang, J. Cai, J. Liu, X. Shen and S. Zhao (2009b). Ionospheric electro-magnetic disturbances prior to Yutian 7.2 earthquake in Xinjiang, China, J. Space Sci., 29, 213-221.

Zhang, X., X. Shen, J. Liu, X. Ouyang, J. Qian and S. Zhao (2009c). Analysis of ionospheric plasma perturbations before Wenchuan earthquake, Nat. Haz. Earth Sys., 9, 1259-1266.

Zhang, X., X. Shen, J. Liu, X. Ouyang, J. Qian and S. Zhao (2010a). Ionospheric perturbations of electron density before the Wenchuan Earthquake, Intl. J. Remote Sens., 31, 3559-3569.

Zhang, X.-M., J. Liu, X.-H. Shen, M. Parrot, J.-D. Qian, X.Y. Ouyang, S.-F. Zhao and J.-P. Huang (2010b). Ionospheric perturbations associated with the $M 8.6$ Sumatra earthquake on 28 March 2005, Chinese J. Geophys., 53, 567-575.

Zhang, X., Z. Zeren, M. Parrot, R. Battiston, J. Qian and X. Shen (2010c). ULF/ ELF ionospheric electric field and plasma perturbations related to Chile earthquakes, Adv. Space Res.; doi: 10.1016/j.asr.2010.11.001.

Zhu, R., D.-M. Yang, F. Jing, J.-Y. Yang and X.-Y. Ouyang (2008). Ionospheric perturbations before Pu'er earthquake observed on DEMETER, Acta Seismol. Sinica, 21, 77-81; doi: 10.1007/s11589-008-0077-8.

Zlotnicki, J., F. Li and M. Parrot (2010). Signals recorded by DEMETER satellite over active volcanoes during the period 2004 August - 2007 December, Geophys. J. Int., $183,1332-1347$.

${ }^{\star}$ Corresponding author: Michel Parrot Université d'Orléans, CNRS, Laboratoire de Physique et Chimie de l'Environnement et de l'Espace, Orléans, France; e-mail:mparrot@cnrs-orleans.fr

(C) 2012 by the Istituto Nazionale di Geofisica e Vulcanologia. All rights reserved. 